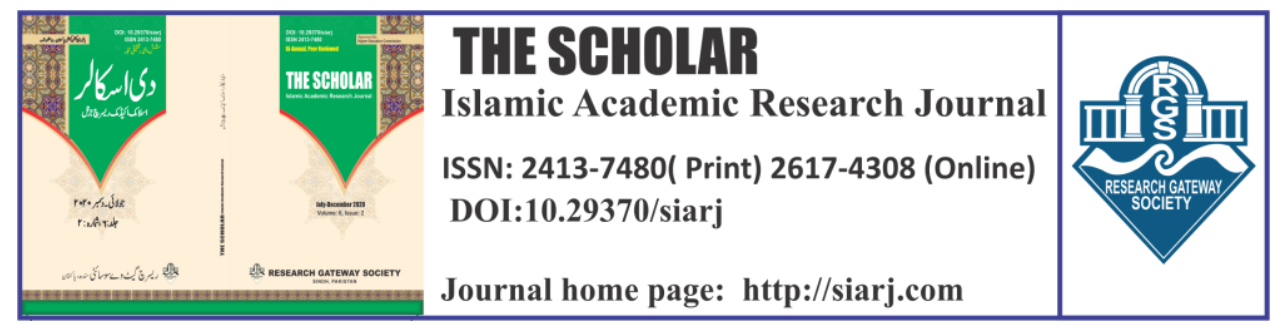

$$
\text { أثر إختلاوف ألفاظ الحديث في تعليل الأحاديث عند الإمام الطبراين "من خلال كتابه المعجم "الأوسط }
$$

\title{
THE EFFECT OF DIFFERENT EXPRESSIONS OF HADITHS ON THE EXPLANATION OF HADITHS ACCORDING TO IMAM AL-TABARANI "THROUGH HIS BOOK AL-MUJAM AL-AWSAT"
}

\section{Abdul Samee Jessar}

Ph.D. Scholar, Department of Hadith, Faculty Usol ud Din, International Islamic University, Islamabad, Pakistan

Email : abdulsamee.jessar@gmail.com

\section{ORCID ID:}

\section{https://orcid.org/0000-0002-9804-8314}

\section{Feth Ur Rehman Gorashi}

Professor, Head of Department of Hadith, Faculty Usool ud Din, International Islamic University, Islamabad, Pakistan. Email:gorashim@gmail.com

\section{ORCID ID:}

\section{https://orcid.org/0000-0002-0998-2835}

To cite this article:

Jessar, Abdul Samee, and Feth Ur Rehman Gorashi. "THE EFFECT OF DIFFERENT EXPRESSIONS OF HADITHS ON THE EXPLANATION OF HADITHS ACCORDING TO IMAM AL-TABARANI 'THROUGH HIS BOOK AL-MUJAM AL-AWSAT.'”' The Scholar-Islamic Academic Research Journal 6, No. 2 (December 30, 2020): 64-91.

\begin{tabular}{|c|c|}
\hline Journal & $\begin{array}{l}\text { The Scholar Islamic Academic Research Journal } \\
\text { Vol. 6, No. } 1 \text { || Janurary -June } 2020 \text { || P. 64-91 }\end{array}$ \\
\hline Publisher & Research Gateway Society \\
\hline DOI: & 10.29370/siarj/ issue11 arabic4 \\
\hline$\overline{\text { URL: }}$ & https://doi.org/10.29370/siarj/ issue11 1arabic4 \\
\hline License: & Copyright c 2017 NC-SA 4.0 \\
\hline Journal homepage & www.siari.com \\
\hline Published online: & $2020-12-30$ \\
\hline
\end{tabular}

To link to this article: https://doi.org/10.29370/siarj/ issue11arabic4

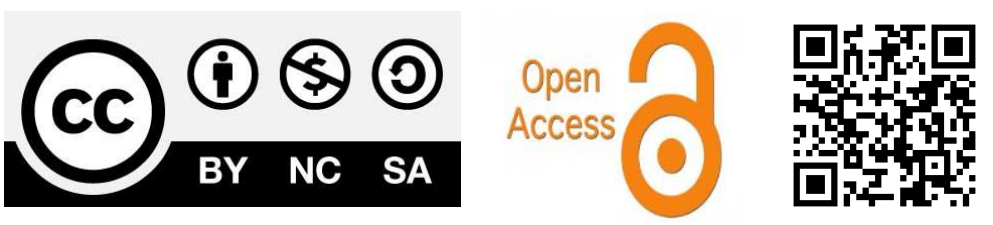




\title{
أثر إختلاف ألفاظ الحديث في تعليل الأحاديث عند الإمام الطبراين "من \\ "خلال كتابه المعجم الأوسط" \\ THE EFFECT OF DIFFERENT EXPRESSIONS OF HADITHS ON THE EXPLANATION OF HADITHS ACCORDING TO IMAM AL-TABARANI "THROUGH HIS BOOK AL-MUJAM AL-AWSAT"
}

Abdul Samee Jessar, Feth Ur Rehman Gorashi

\begin{abstract}
Imam al-Tabarani is one of the great scholars of Islam and the well-known person in Islamic World, He was the "Musnad Duniyah" Umamah rely on Him about Prophet's (peace be upon him) Narrations. Al Muajm Al-Awast is most important Book of Hadith especially in ELAL (some hidden reason effect on Hadith), He said: "This is my Soul" its means core of his Knowledge, Subject of This Book collect Poor chain of Narrations, Method of Imam Al Tabrani comment every Hadith, and indicate Tafrud (singular chain or text of narration), or indicate conflict between narrators in the narration. I (Researcher) make title: "The explanation of Imam alTabarani by changing the body text in The Al-Mujam al-Awsat", take some Hadiths form This Book about some words of Hadith changed that can be right and can be wrong, can be same meaning, can be differ to each other, so I explain what kind of changing.
\end{abstract}

KEYWORDS: Al Tabrani, Al Mujam Al Awast, Hadith, Hidden Reason, Body Text.

العلة، ألفاظ المتن. الحديث، الكلمات المفتاحية: الطبراني، المعجم الأوسط 


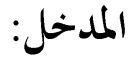

"أبو القاسم سليمان بن أحمد اللخمي الشامي، أحد الأئمة المعروفين والحفاظ المكثرين

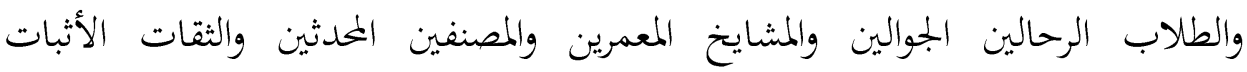

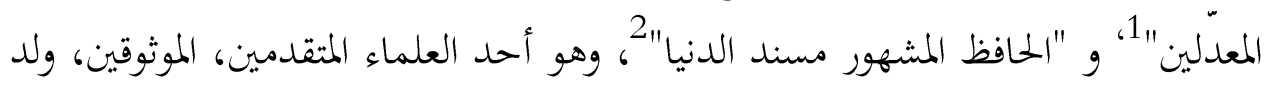

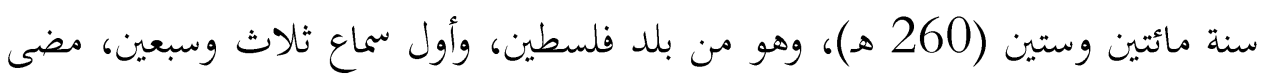

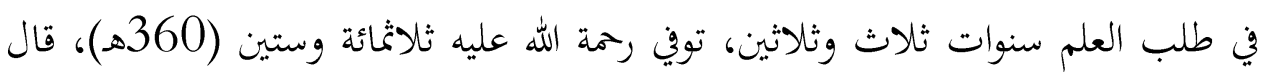

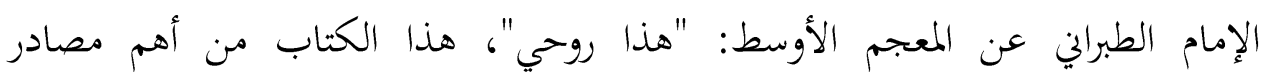

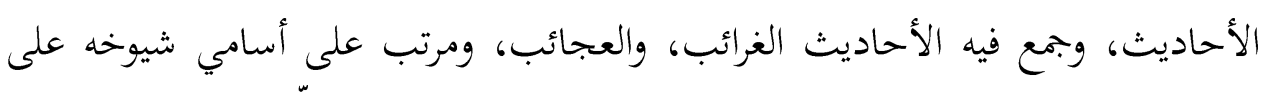

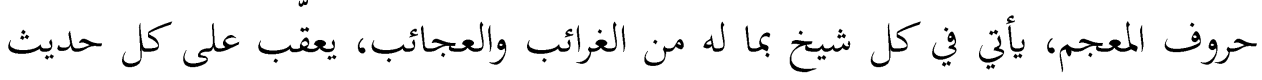

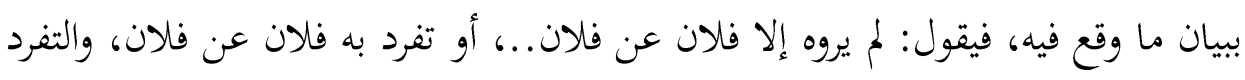

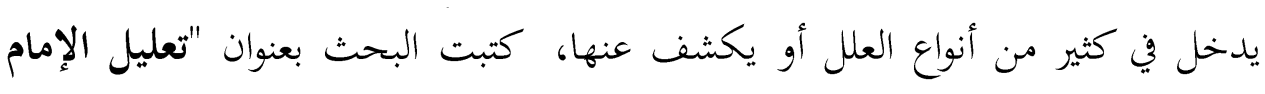

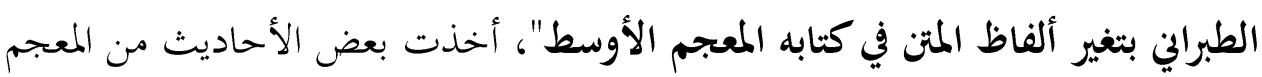

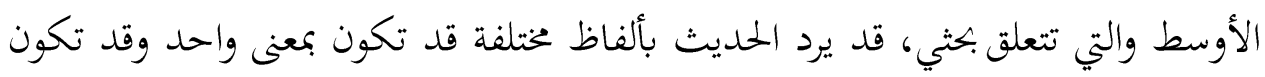

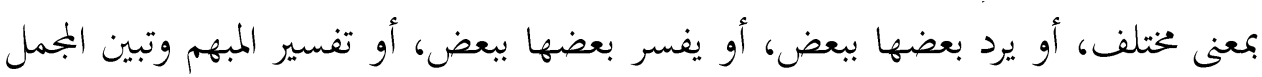

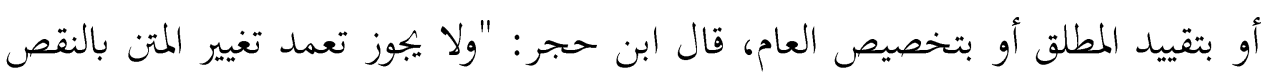

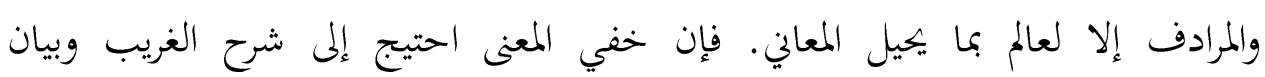

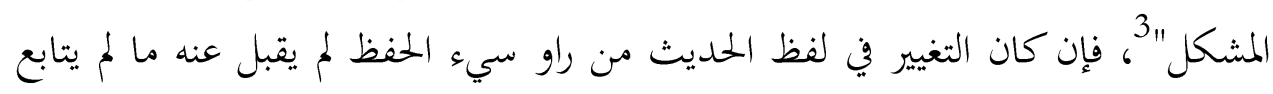

1 - Al Hamvi, abu Abdul Allah Shehab Din Yaqot bin Abdul Allah Rumi, Mujam Al-Buldan, Beirut, Dar ul Sadir, 1995, V.4, P.18.

2 - Al-Dhahabi, Shams-ul-Din Abu Abdillah Muhammad bin Ahmad bin Uthman, Tareek Al Islam wa Wafiyat Al Masheer, Al Alaam, Dar Al Garb Al Islami, 2003, V.8, P.143.

3 - Al-Asqalani, Abu Fazl Ahmad bin Ali bin Muhammad bin Ahmed bin Hajar, Nuzhat al Nazr fi Nukbat Al Fikr, Riyaz, Matbat Safeer, 1422 A.H, P.277. 
عليه، فينظر من كلام الأئمة، فإن كان له متابعات فإنه يزول الإشكال، أذكر بعض أمثلة من هذا النوع حتى يتبين نوع العلّة علة؟، هل هي قادحة أو غير قادحة؟، وهل هي مؤثرة أو غير مؤثرة؟، وهل هي مقبولة أو الو

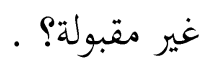

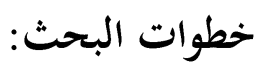
اقتضت طبيعة هذا البحث أن يسير وفق الخطة الآتية: منهج الإمام الطبراني في تعليل بتغير ألفاظ المتن في كتابه المعجم الأوسط. أمثلة تطبيقية من كتاب الإمام الطبراني المعجم الأوسط في تعليل بتغير ألفاظ المتن. - مثال الأول علة غير مؤثرة من تغير لفظا دون معنا يمكن جمع بينها. - مثال الثاني علة مؤثرة من تغير اختلاف لفظا ومعنا لا يمكن مجع بينها. - مثال الثالث علة مؤثرة من تغير تخليط وتبديل لا يمكن جمع بين بعض ألفاظها. - مثال الرابع علة مؤثرة من تغير زيادة لفظا لا يمكن قبول زيادة لفظها. - مثال الخامس علة مؤثرة من تغير عدد لا يمكن قبول تفاوتما. - - مثال السادس علة مؤثرة من تغير ألفاظ التى خالف متنها، وسائر قصتها. - - نتائح البحث -

منهج الإمام الطبراني في تعليل بتغير ألفاظ المتن في كتابه المعجم الأوسط: بين لي من خلال هذا البحث أن منهج الإمام الطبراني في تغير ألفاظ المتون بثلاث

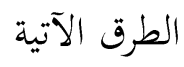




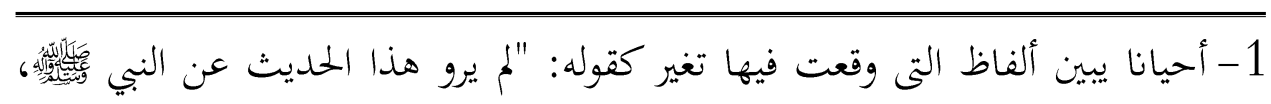

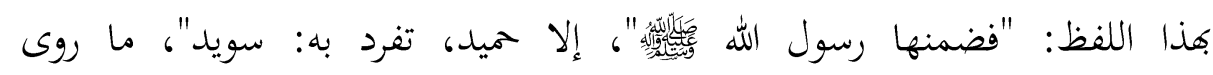

$$
\text { "فضمنها"، ولا "استعار" عن حميد إلا سويد بن عبد العزيز وهو ضعيف جدا. }
$$

2- وأحيانا يبين تفرد الراوي في اللفظ دون ذكر ما هي كقوله: "لم يرو هذا الحديث عن

سهيل، بهذا اللفظ، إلا زهير بن عُمََّّ، ما روى "صوموا تصحوا" عن سهيل إلا زهير

$$
\text { بن عُمَّمَ. }
$$

3- وأحيانا يشير تفرد الراوي دون ذكر ما تفرده من المتن ولا ذكر اللفظ كقوله: "لم يرو

هذا الحديث عن هشام بن عروة إلا عبدة" أي لم يرو اللفظ عذرة عن هشام بن عروة

إلا عبدة، وقوله: "لم يرو هذا الحديث عن هشام إلا فرج بن فضالة، تفرد به مُحُّمّ بن

بكير"، ما روى "لنغلل لحية" إلا فرج بن فضالة، وقوله: "ملم يرو هذا الحديث عن علباء

بن أحمر إلا الحسين بن واقد"، ما روى البعير عن عشرة إلا الحسين بن واقد وكقوله:

"امل يرو هذا الحديث عن ابن جريج، إلا البرساني"، ما روى سحر الشمس إلا عُمَّمَ بن

$$
\text { بكر البرساني، ما بين الإمام الطبراني فقط أشار تفردهم . }
$$

أمثلة تطبيقية من كتاب الإمام الطبرتي المعجم الأوسط في تعليل بتغير ألفاظ المتن:

سأذكر ستة أمثلة التى يتعلق موضوعنا، ومنهج بكثي في تحقيق الحديث مما يلى

$$
\text { أولا: أورد متن الحديث من المعجم الأوسط. }
$$

ثانيا: تشريح بعض ألفاظ مشكلة التى جاء في الحديث من الكتب المعاجم.

$$
\text { ثالثا: تخريج الحديث من الكتب الأحاديث. }
$$




$$
\begin{aligned}
& \text { رابعا: دراسة الحديث فيها بيان درجة الرواة، وتشريح تعليق الإمام الطبراني، وأقوال } \\
& \text { العلماء إذا أشكل شيء. } \\
& \text { خامسا: إبراز العلة ما العلة في الحديث أبين مختصرا. } \\
& \text { سادسا: رأي الباحث أبين فيها قول الراجح من بعد تفهم ألفاظ، وبحمع الطرق، } \\
& \text { وتدرس السند، وتعمق المتن. }
\end{aligned}
$$

\section{- مثال الأول علة غير مؤثرة من تغير لفظا دون معنا يمكن جمع بينها:}

قال الإمام الطبرابي رحمه الله: حدثنا موسى بن هارون، نا تُحَّة بن عبد الله بن

نمير، نا عبدة بن سليمان، عن هشام بن عروة، عن أبيه، عن عائشة، اأَلَّ النَّيَّ صلى الله

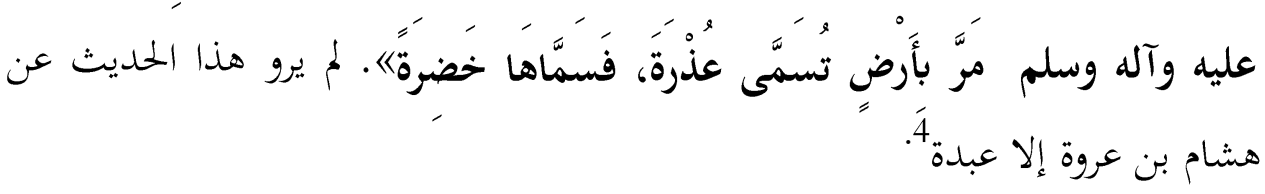

ألفاظ المشكلة: خضرة: "من القرى المتقدمة في آرة، وأرض لمحارب بنجد"5 و "على معنى التفاؤل حتى تحضر "6 ، و غدرة: "كانت لا تسمح بالنبات أو تسرع إليه الآفة فكأنه غادر

${ }^{4}$ - Al Tabrani Abu Al Qasim Sulemaan bin Ahmed, Al Mujam Al Awast, Dar Al Harmain, Al Qaahira, 1995, V.8, P.75, Hadith no: 8008.

5 - Al Samhavi Ali Bin Abdul Allah bin Ahmad, Wafa Al Wafa b Akbaar Dar Al Mustfa, Dar Al Kutob Al Almiyah, Beirut, 1419 A.H, V.4, P.68.

${ }^{6}$ - Al Bagvi Abu Muhammad Al Hussain bin Masaud, Srah Al Sunnah, Al Maktab Al Islami, Damscus, 1983, V.12, P.344. 
أثث إختلاف ألفاظ الحديث في تعليل الأحاديث عند الإمام الطبراني "من خلال كتابه المعجم الأوسط

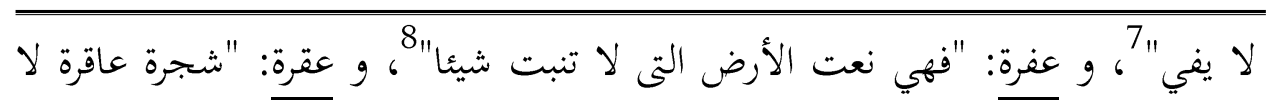

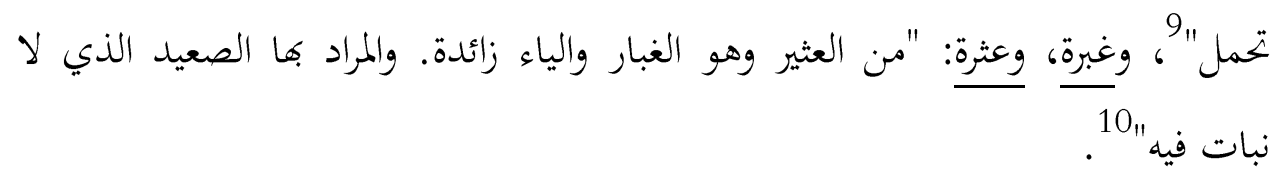

تخريج الحديث: أخرج الأئمة: الطبراني في المعجم الأوسط (1) 2022) 648، وابن حبان في صحيحه (136\13) 5821، وأبو يعلى في مسنده (42\8) 4556، وأبو سليمان الخطابي في غريب الحديث (11) الحديث (1255\) 131، والطحاوي في شرح مشكل الآثار (5\54) 1049، من طرقهم عن عبدة بن سليمان، والطبراني في المعجم الأوسط (3\33 153) 2766، عن عُحَّم بن الحسن، وفي المعجم الصغير (118) 349، والخطيب البغدادي في تاريخ بغداد 2454 (356\8، عن شريك، والترمذي في سنه (5 (135) 2839، عن عمر بن علي المقدمي، روى عبدة، و مُحَّة بن الحسن، وشريك كلهم عن هشام بن عروة، عن أبيه،

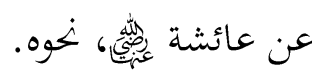

7 - Al Kujrati Jamal ud Din Muhammad Tahir Al Hindi, Majmah Bihaar Al Anwaar Fi Garaib Al Tanzeel, w Lataef Al Akbaar, Matb Majlis Daerh Al Marif Al Usmaniyah, 1967, V.4, P.11.

${ }^{8}$ - Al Bagvi Abu Muhammad Al Hussain bin Masaud, Srah Al Sunnah, V.12, P.344.

9 - Al Jazri Al Shebani Majd ud Din Abu Al Sadaat Al Mubarik Bin Muhammad (Ibn Aseer), Al Nihayah Fi Gareeb Al Hadith W Al Asr, Al Maktab Al Ilmiyah, Beirut, 1979, V.3, P.273.

${ }^{10}$ - Ibn Aseer, Al Nihayah Fi Gareeb Al Hadith W Al Asr, V.3, P.182 
أثر إختلاف ألفاظ الحديث في تعليل الأحاديث عند الإمام الطبراني "من خلال كتابه المعجم الأوسط

دراسة علة الحديث: رجال الطريق الإمام الطبراني كلهم ثقات: موسى بن هارون: "ثقة

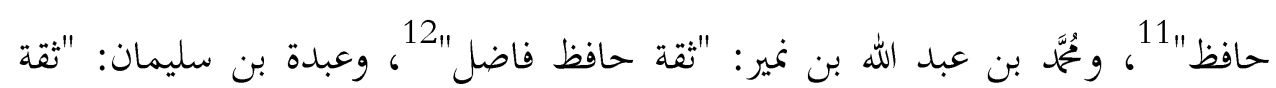

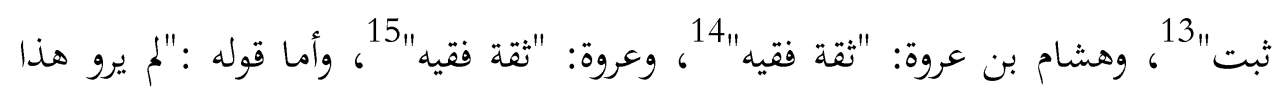
الحديث عن هشام بن عروة إلا عبدة"، ولكن وجدت تابع عبدة سليمان ثلاث آخرون شريك بن عبد الله، و وُمَّمَ بن الحسن وعمر بن علي المقدمي كلهم عن هشام بن عروة عن أبيه عن سيدة عائشة عزئِّ. * - غَدرةً" روى الأئمة: أبو يعلى الموصلى في مسنده 16، وابن حبان في صحيحه عن الحسن بن سفيان، والطحاوي في مشكل الآثار عن عُمَّمَ بن علي بن داود، وقاسم بن ثابت بن حزم العوفي السرقسطي في دلائل في غريب الحديث 17 عن موسى بن هارون، روى أبو يعلى، وابن سفيان، و مُحَّم بن علي، وموسى بن هارون (براوية السرقسطي) كلهم عن عُمَّمَ بن عبد الله بن نمير عن عبدة بن سليمان عن هشام بن عروة عن أبيه عن أم

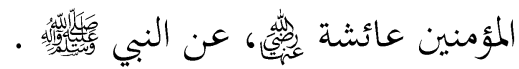

11 - Al-Asqalani, Abu Fazl Ahmad bin Ali bin Muhammad bin Ahmed bin Hajar, Takreeb Al Tahzeeb, Sirya, Dar Al Raseed, 1986, P.554.

12 - Al-Asqalani, Ibn Hajar, Takreeb Al Tahzeeb, P.490.

13 - Al-Asqalani, Ibn Hajar, Takreeb Al Tahzeeb, P.369.

${ }^{14}$ - Al-Asqalani, Ibn Hajar, Takreeb Al Tahzeeb, P.573.

15 - Al-Asqalani, Ibn Hajar, Takreeb Al Tahzeeb, P.389.

16 - Al Mosali Abu Yala Ahmad Bin Ali Bin Usman, Musnad Abi Yala, Dar Al Mamon 1 Turaas, Damascus, 1984, V.8, P.42, Hadith no: 4556.

17 - Al Sarqasti Qasim bin Sabit, Al Dalael Fi Gareeb Al Hadith, Maktab Al Abikaan, Riyaz, 2001, Riyaz, V.1, P.255, Hadith no: 131. 
أثر إختلاف ألفاظ الحديث في تعليل الأحاديث عند الإمام الطبراني "من خلال كتابه المعجم الأوسط

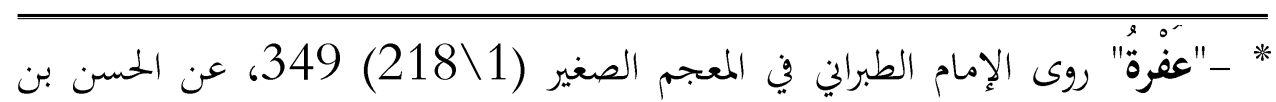
علي عن سعيد بن يهيى عن إسحاق عن شريك عن هشام، عن أبيه عن أم المؤمنين عائشة

* - عقَرةً" روى الحربي في غريب الحديث عن عبد الله بن عون عن عبدة عن هشام. والخطيبَ في تاريخ بغداد عن عُمَّل بن عبد الله شهريار عن سليمان بن أحمد بن أيوب عن الحسن بن علي عن سعيد بن الأزهر عن إسحاق الأزرق عن شريك عن هشام عن أبيه عن أم المؤمنين عائشة عإِّى . * - "عذرة" روى الطبراني في المعجم الأوسط عن أحمد بن علي بن مسلم وموسى بن هارون عن تُحَّة بن عبد الله بن نمير عن عبدة بن سليمان عن هشام. ورواه البيهقي في

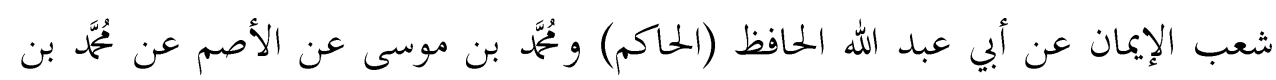
إسحاق الصنعاني عن ابن نمير عن عبدة عن هشام.

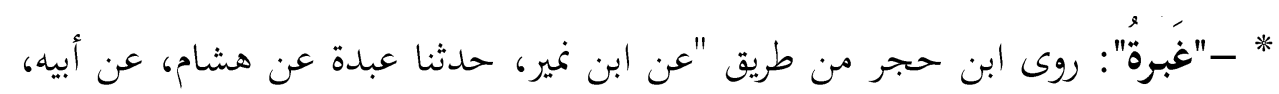

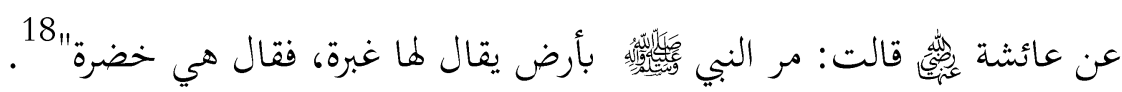
* - "العَّرَ": ما وجدت سند ولكن ذكرها ابن الأثير في النهاية في غريب الحديث 19. روايات فيه "غدرة" أو "عذرة" أقوى من غيرها قد أخرج أبو يعلى الموصلى في مسنده عن ابن عبد الله بن عون20، وابن حبان في صحيحه، والطحاوي في مشكل الأثار، وقاسم

18 - Al-Asqalani, Ibn Hajar, Al Malib Al Aleyah B Zawaed Al Masaned Al Samaniyh, Dar Al Asimah, Saudi Arb, 1419 A.H, V.12, P.147.

19 - Ibn Aseer, Al Nihayah Fi Gareeb Al Hadith W Al Asr, V.3, P.182.

${ }^{20}$ - Al Mosali Abu Yala Ahmad Bin Ali, Musnad Abi Yala, V.8, P.42, Hadith no: 4556. 
العوفي السرقسطي في الدلائل في غريب الحديث، وإبراهيم بن فراس كلهم يروون عن عُمَّمَ بن عبد الله بن نمير عن عبدة عن هشام إلخ "غدرة". رجال رووا عن ابن عبد الله ابن نمير: عُمَّم بن علي بن داود-ثقة- والحسن بن سفيان-ثقة- وأبو يعلى الموصلي-ثقة مأمونوموسى بن هارون-ثقة حافظ-بطريق ابراهيم بن فراس-ثقة-كلهم عن ابن نمير "غدرة". وعنه-ابن نمير- موسى بن هارون-ثقة مأمون-(بطريق الطبراني) وأحمد بن علي-ثقة حافظ- ومُحَّم بن إسحاق الصنعاني-ثقة ثبت- كلهم روواه عنه: "عذرة". لعل "غدرة" أقوى من "عذرة" بقرائن أخرى مثل ذكر ابن حبان في صحيحه "غدرة". ويف رواية "عقرة" شريك تابعه عبدة ولكن شريك-صدوق سئ الحفظ- وفيه مُحَّم بن عبد الله بن شهريار --جهول الحال-، وعبد الله بن عون -ثقة- ولكن أكثر جمعا وقوة رووا غيرها وايضا هناك اختلاف فيما رووا عن شريك عن الحسن بن علي-ثقة- عن سعيد بن يهيىثقة- عن اسحاق الأزهر-ثقة مأمون- عن شريك: "عفرة" وعن طريق ابن عبد الله بن شهريار "عقرة". و "غبرة" ذكر إلا ابن حجر في مطالب العالية روى عن ابن نمير، ولكن رواة الذين رووا عن ابن نمير خلاف ذلك. وأما "عثرة" و "عزرة" ما وجدت سندا. إبراز العلة: وقع اختلاف في اللفظ "عذرة" من الرواة. رأي الباحث قلت : تغير هذه ألفاظ لا تؤثر على الحديث لعدة أسباب 1 - ربما تسمية تلك القرية لها أكثر اسما. 2- شكل وصوت هذا ألفاظ متماثلة: غدرة، عذرة، وعفرة، وعقرة، غبرة، عثرة. 3- معنى هذا الفاظ متقاربة: الأرض لا تنبت، أو شجرة لا تحمل، كل هذا لا تؤثر.

ثهال الثاني علة مؤثرة من تغير اختلاف لفظا ومعنا لا يمكن جمع بينها: 
قال الإمام الطبرائ رحمه الله: حدثنا موسى بن جمهور، ثنا أبو تقي، نا سويد بن

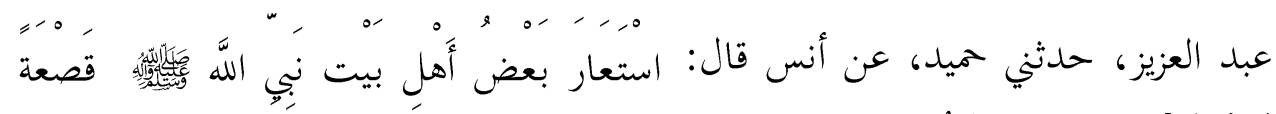

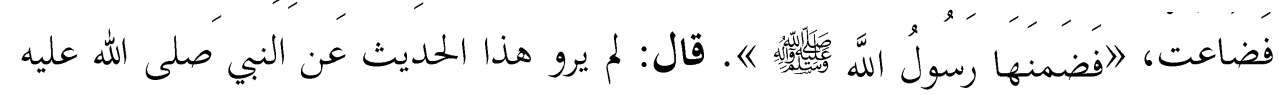

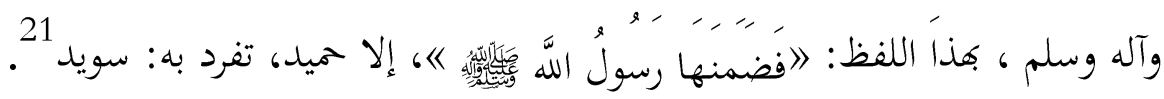
ألفاظ المشكلة: استعار: "الشيء منه طلب أن يعطيه إياه عارية"22، و قصعة: "وعاء يؤكل فيه ويثرد وكان يتخذ من الخشب غالبا"232، و ضاع: "فقد وأهمل "24، و ضمن: "التزم أن يؤدي عنه ما قد يقصر في أدائه"25.

تخيج الحديث: أخرج الأئمة: الترمذي في سننه (3\633) 1360، وعبد الرحمن بن حمدان النصروي في أمالى أي سعد البصروي (67)، والطبراني في المعجم الأوسط (7348) من طرقهم عن سويد بن عبد العزيز عن حميد الطويل عن أنس عِّفّه، نهوه. وروى الأئمة: البخاري في "صحيحه" (136\3) 2481، من طريقه عن يهيى بن

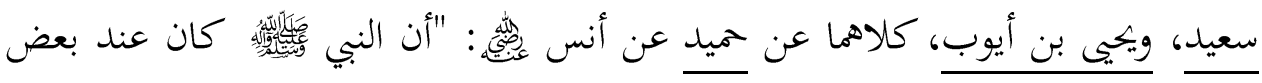
نسائه، فأرسلت إحدى أمهات المؤمنين مع خادم بقصعة فيها طعام، فضربت بيدها،

21 - Al Tabrani Abu Al Qasim Sulemaan bin Ahmed, Al Mujam Al Awast, V.8, P.163, Hadith no: 8280 .

22 - Al Mujam Al Waseet, Ibraheem Mustfa, Ahmed Al Ziyat, Hamid Abdul Qadir, Muhammad Al Najaar (Majmuh Al Lugat Al Arbiya), Dar Al Dawat, Qahira, V.2, P.636.

23 - Al Mujam Al Waseet, Majmuh Al Lugat Al Arbiya, V.2, P.740.

24 - Al Mujam Al Waseet, Majmuh Al Lugat Al Arbiya, V.1, P.547.

25 - Al Mujam Al Waseet, Majmuh Al Lugat Al Arbiya, V.1, P.544. 
فكسرت القصعة، فضمها وجعل فيها الطعام، وقال: \كلوا《 وحبس الرسول والقصعة حتى فرغوا، فدفع القصعة الصحيحة، وحبس المكسورة"، و (36\7) 5225، من طريقه

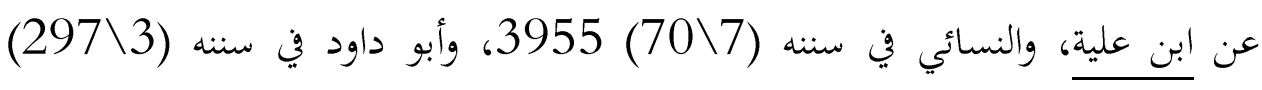
3567، وابن ماجه في سننه (782\2) 2334، من طرقهم عن خالد بن الحارث،

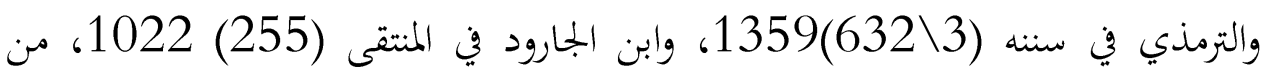
طريقينهما عن سفيان الثوري، وأحمد في مسنده (19\84) 12027، عن ابن أبي عدي، والدارمي في سننه (3) 1692) 2640، وأبو يعلى في مسنده (355) 3849، وابن أبي شيبة في مصنفه (301\3) 36282، من طرقهم عن يزيد بن

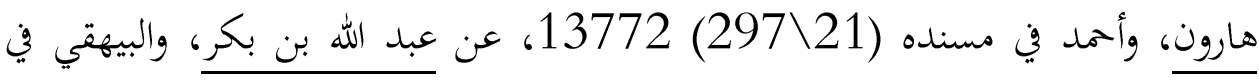
السنن الكبرى (159\6) 11522، من طريقه عن بشر بن المفضل، وأبو نعيم في تاريخ أصبهان (262\2) من طريقه عن أبي حماد الحنفي، كلهم عن حميد عن أنس رضي الله

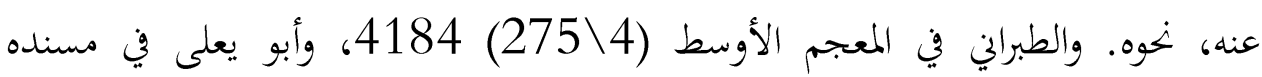

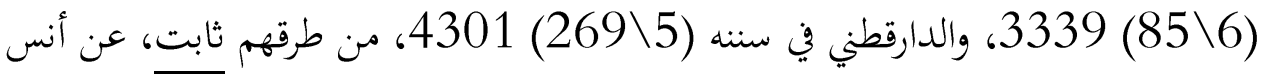

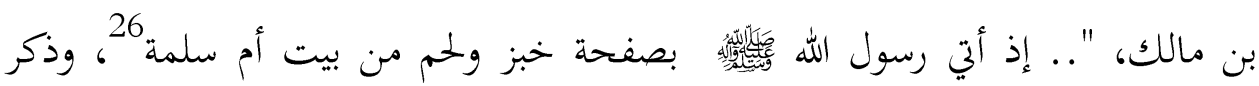
القصة مثل رواية صحيح البخاري ليس ذكر فها استعار ولا ضمان وعاء.

\footnotetext{
${ }^{26}$ - Al Tabrani Abu Al Qasim Sulemaan bin Ahmed, Al Mujam Al Awast, V.4, P.275, Hadith no: 4184.
} 
دراسة علة الحديث: رجال الطريق الإمام الطبراني: موسى بن جمهور : "ثقة"27، وأبو تقي

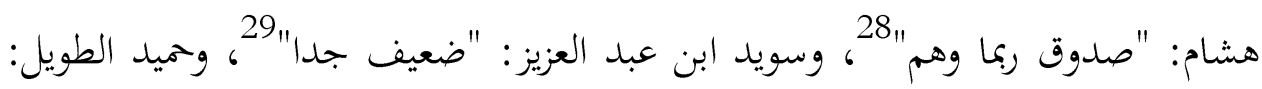

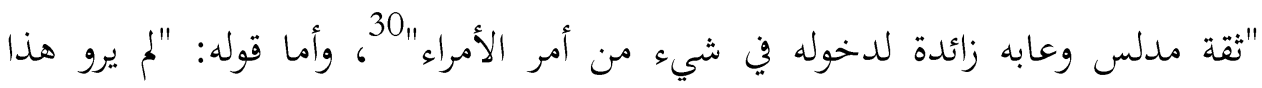

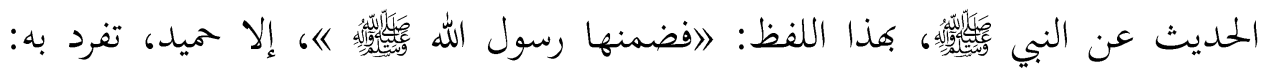
سويد"، نعم ما روى اللفظ "فضمنها" و "أستعار" إلا سويد بن عبد العزيز وهو ضعيف، رجح الإمام الترمذي في تعقيب هذا الحديث خلاف حديث سويد قال: "سويد بن عبد العزيز رجل كثير الغلط في الحديث - والصحيح عندي ما رواه سفيان الثوري عن حميد،

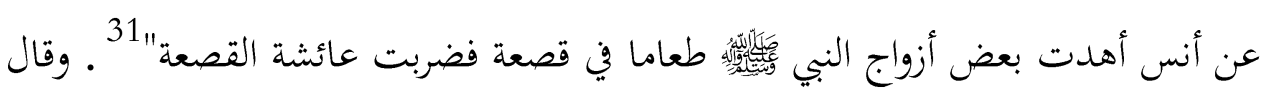

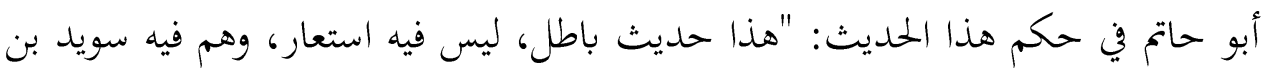

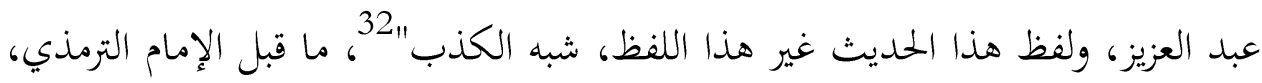
وأبو حاتم الرازي التميمي حديث سويد بن عبد العزيز.

إبراز العلة: ما روى "فضمنها"، و"استعار" عن حميد عن أنس هُّذّ، إلا سويد بن عبد العزيز.

27 - Al Jazri Shams Ud Din Abu Al Khair Ibn Al Jazri, Gayah Al Nihayaht Fi Tabqaat Al Quraa, Maktab Ibn Tamiyah, 1351 A.H, V.2, P.318.

28 - Al-Asqalani, Ibn Hajar, Takreeb Al Tahzeeb, P.573.

29 - Al-Asqalani, Ibn Hajar, Takreeb Al Tahzeeb, P.260

${ }^{30}$ - Al-Asqalani, Ibn Hajar, Takreeb Al Tahzeeb, P.181.

31 - Al Termzi Abu Esa Muhammad Bin Esa, Ilil Al Kabeer, Maktab Al Nahzht Al Al Arbiyat, Beirut, 1409 A.H, P.208, Hadith no: 370.

32 -Al Tamimi Al Hanzli Al Razi Abu Muhammad Abdul Rehman Bin Muhammad, Al Al Ilil, Matabih Al Hamizi, Al Riyaaz, 2006, V.4, P.265-266, Hadith no: 1412. 
رأي الباحث قلت: تغير هذه ألفاظ تؤثر على الحديث لعدة أسباب

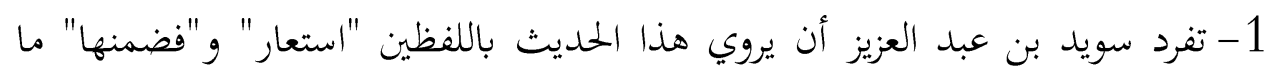

$$
\text { روى غيره. }
$$

2- طريق الإمام الطبراني ضعيف: سويد بن عبد العزيز ضعيف، لا يقبل منه تفرد.

3- مخالفة ثقات: روى يميى بن سعيد ويجيى بن أيوب، وسفيان الثوري وغيرهم عن حميد،

$$
\text { وهم ثنقات. }
$$

4- خخالفة جماعة: خالف سويد: يهيى بن سعيد، ويميى بن أيوب، وابن علية، وسفيان

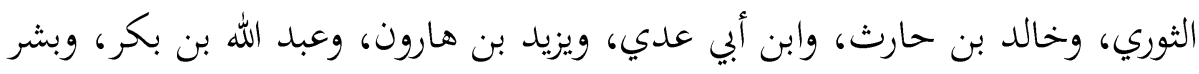

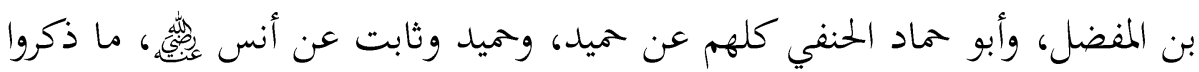
"استعار"، ولا "فضمنها".

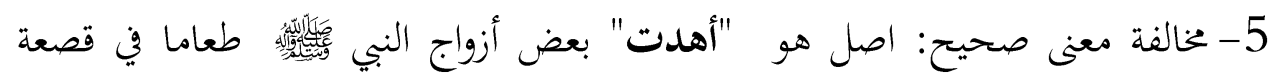
فضربت عائشة القصعة فكسرت، "فضمها" غير ضمان. كما واضح في الرواية الإمام

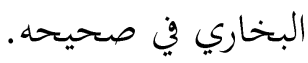

مثال الثالث علة مؤثرة من تغير تخليط وتبديل لا يمكن جمع بين بعض ألفاظها: قال الإمام الطبراني رحمه الله: حدثنا موسى بن زكريا، نا جعفر بن يُمَّمَ بن فضيل

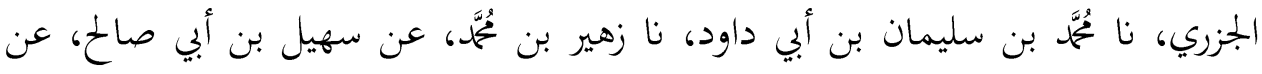

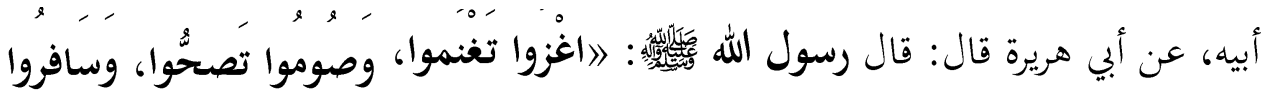




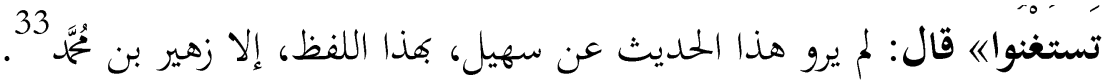

ألفاظ المشكلة: اغزوا: من غزا "العدو غزوا وغزوانا سار إلى قتالهم وانتهابهم"34"، و تغنموا: من غنم "الشيء غنما فاز به والغازي في الحرب ظفر بمال عدوه"35 و و تستغنوا: مصدر غنى، "استغنى اغتنى وبه اكتفى"36 ، أي كثر مال، ولا يحتاج شيء.

تخريج الحديث: أخرج الشهاب في مسنده 36413، 622 من طريقه مُحَّم بن عبد الرحن بن الرداد، عن سهيل بن أبي صالح، عن أبيه، عن أبي هريرة، قال: قال رسول الله

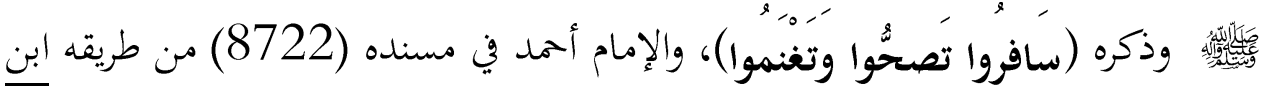

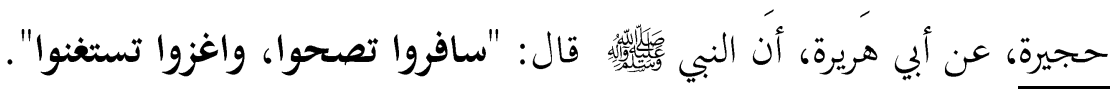

دراسة علة الحديث : رجال الطريق الإمام الطبرائ: - موسى بن زكريا التستري: "ضعيف

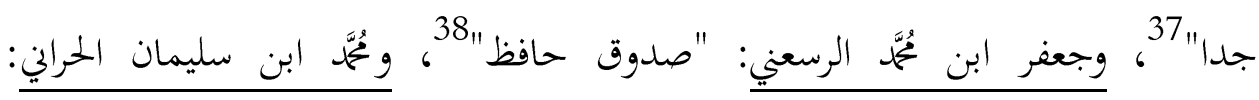
"صدوق"393 وزهير ابن عُمَّم التميمي: "ثقة إلا أن رواية أهل الشام عنه غير مستقيمة

33 - Al Tabrani Abu Al Qasim Sulemaan bin Ahmed, Al Mujam Al Awast, V.8, P.174, Hadith no: 8312.

${ }^{34}$ - Al Mujam Al Waseet, Majmuh Al Lugat Al Arbiya, V.2, P.652.

35 - Al Mujam Al Waseet, Majmuh Al Lugat Al Arbiya, V.2, P.664.

36 - Al Mujam Al Waseet, Majmuh Al Lugat Al Arbiya, V.2, P.665.

37 - Al Munsori Abu Al Tiyab Nayaf Bin Salah, Arshad Al Qasi W Dani Ela Tarajm Sheyok Al Tabrani, Dar Al Kiyaan, Al Riyaaz, P.655-656.

38 - Al-Asqalani, Ibn Hajar, Takreeb Al Tahzeeb, P.141.

39 - Al-Asqalani, Ibn Hajar, Takreeb Al Tahzeeb, P.481. 
فضعف بسببها" "40، وسهيل ابن أبي صالح: "صدوق تغير حفظه بأخرة" ${ }^{41}{ }^{4}$ وذكوان أبو

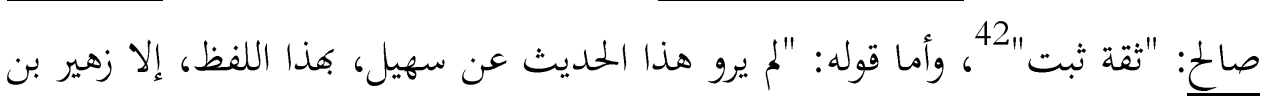

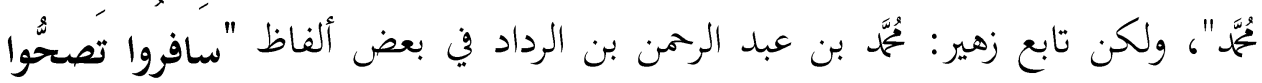

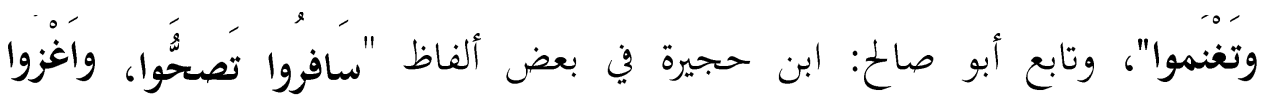

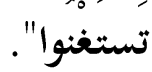
أورد الشيخ أبو جعفر العقيلي في كتابه الضعفاء الكبير حديث زهير بن مُحمَّم

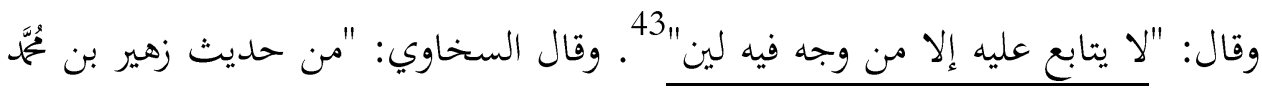

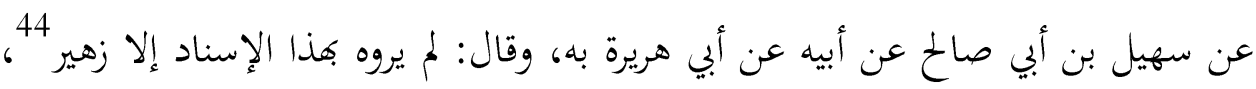
وذكر بعض شواهد للحديث زهير ولكن ليس مطابق تماما، بعضها مطولا: في رواية ابن

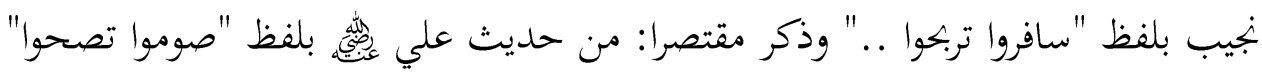
ومن حديث ابن عمر رضي الله عنهما بلفظ "سافروا تصحوا وتسلموا"، ومن حديث أبي تركي سعيد رضي الله "سافروا تصحوا"، وجاء عدة شواهد حديث زهير بن يُمجّم ولكن غير

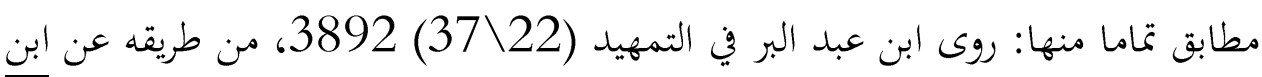

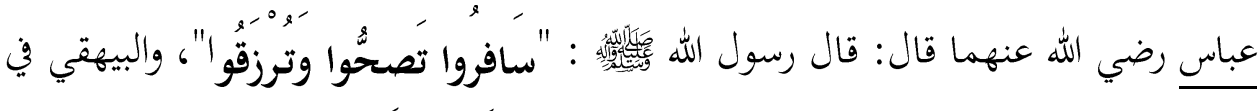

${ }^{40}$ - Al-Asqalani, Ibn Hajar, Takreeb Al Tahzeeb, P.217.

${ }^{41}$ - Al-Asqalani, Ibn Hajar, Takreeb Al Tahzeeb, P.259.

${ }^{42}$ - Al-Asqalani, Ibn Hajar, Takreeb Al Tahzeeb, P.203.

43 - Al Oqalee Abu Jafer Muhammad Bin Umr, Al Dhafaa Al Kabeer, Dar Al Maktab Al Ilmiyaht, Beirut, 1984, V.2, P.92.

${ }^{44}$ - Al Sakaavi Shams Ud Din Abu Kair Muhammad Bin Abdul Rehman, Al Maqasid Al Hasnat Fi Biyaan kaseer min Al Ahadith Al Mashthart Ala Alsinat, Dar Al Kitaab Al Arbi, Beirut, 1985, P.381, Hadith no: 549. 
The Scholar Islamic Academic Research Journal

Vol. 6, No. 2 || Janurary-June 2020||P.64-91

https://doi.org/10.29370/siarj/issue11arabic4

السنن الكبرى (101\7) 12589، من طريقه ابن عمر رضي الله عنهما، قال: قال رسول الله إبراز العلة: تخليط وتبديل ألفاظ الحديث.

رأي الباحث قلت: طريق الإمام الطبراني ضعيف جدا، جاء متن هذا الحديث عدة تغيرات

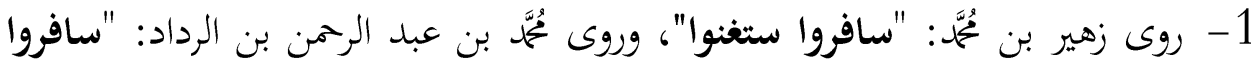
تصحوا وتغنموا"، زاد في سفر غنيمة، وما ذكر غزو ولا صوم.

2- روى زهير بن مُحَّ، "اغزوا تغنموا، وصوموا تصحوا، وسافروا تستغنوا"، وروى ابن

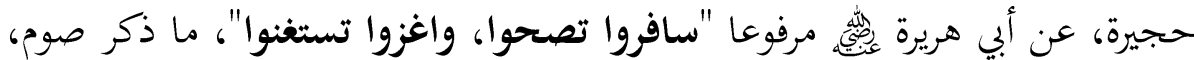
وذكر صحة في سفر، رواية ابن حجيرة أقوى في "سافروا وتصحوا". 3- ما وجدت متابع في الفظ "صوموا تصحوا" هذا زيادة في الرواية زهير بن مُحمَّما ما روى غيره، وهذا غير محفوظ لضعف السند، وعدم متابع، وتخليط الفاظ.

هـ مثال الرابع علة مؤثرة من تغير زيادة لفظا لا يمكن قبول زيادة لفظها:

قال الإمام الطبرالين : حدثنا موسى قال: نا يُمَّمَ بن بكير قال: نا فرج بن فضالة،

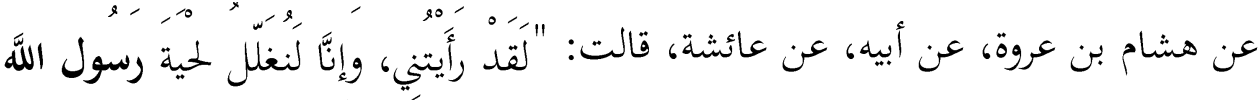




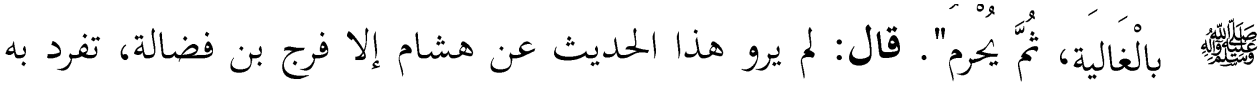

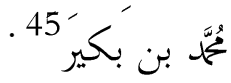

ألفاظ المشكلة: غلل من تغلل "الشيء انغل فيه وبالغالية تطيب بها"46، و غالية: "أخلاط من الطيب كالمسك والعنبر"

تخريج الحديث : من روى "لحية"، و "بالغالية" أخرج الأئمة: أبو بكر ابن عبدويه البزاز

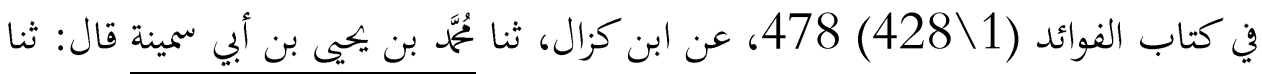

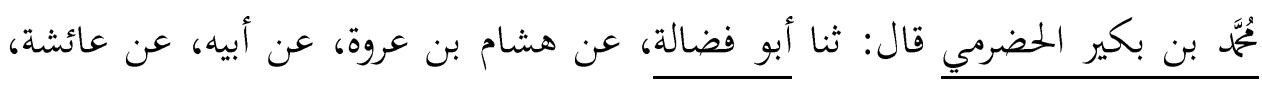

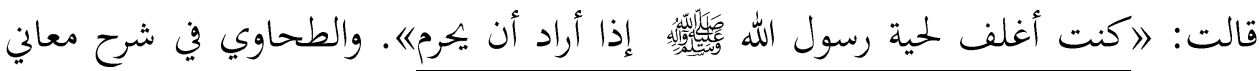

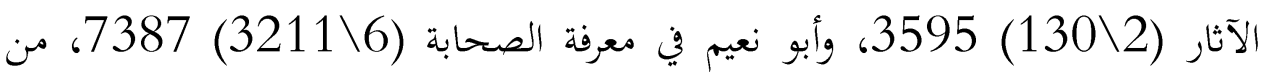

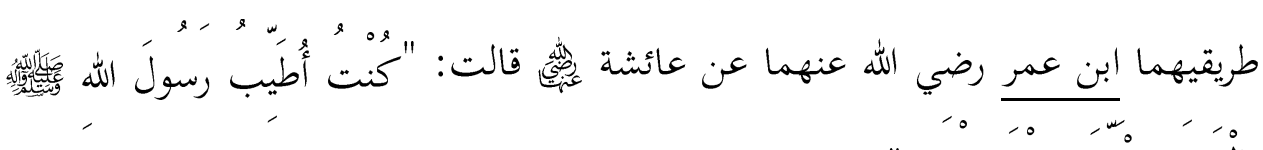
بالغالية الجيدية عند إحرامه".

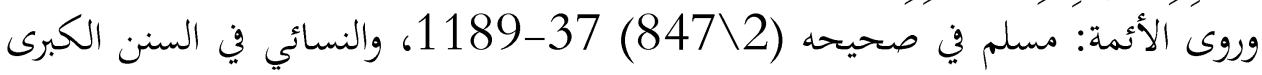
3656، وأحمد في مسنده (31\4) (171\42) 25287، من طرقهم عن عثمان بن عروة، والدارقطني في سننه (325\3) 2677، من طريقه عمرو بن شعيب، روى

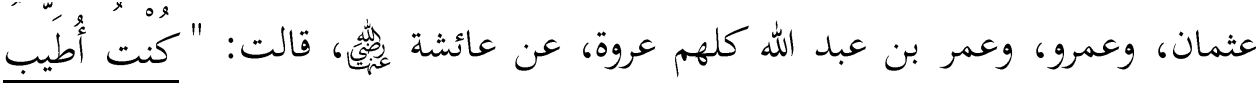

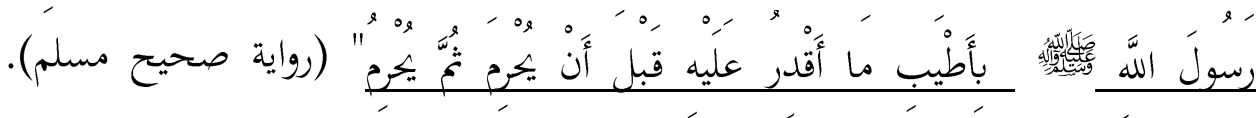

${ }^{45}$ - Al Tabrani Abu Al Qasim Sulemaan bin Ahmed, Al Mujam Al Awast, V.8, P.215, Hadith no: 8439 .

${ }^{46}$ - Al Mujam Al Waseet, Majmuh Al Lugat Al Arbiya, V.2, P.660.

47 - Al Mujam Al Waseet, Majmuh Al Lugat Al Arbiya, V.2, P.660. 
والبخاري في صحيحه (5930) من طريقه عن عمر بن عبد الله بن عروة، سمع عروة، والقاسم، وابن حبان في صحيحه (85\9) 3771، من طريقه عن عبد الرحمن بن القاسم، عن أبيه، وأبو داود الطيالسي في مسنده (136\3) 1657، وإسحاق بن راهويه في مسنده (5399\21213 1121، وابن حبان في صحيحه (194\1) 3881، من طرقهم عن سالم بن عبد الله بن عمر، وأبو داود الطيالسي في مسنده (94\3)

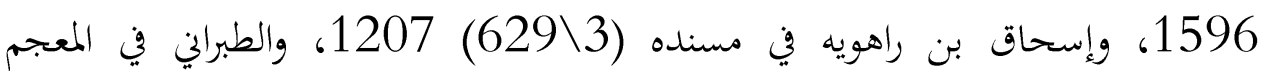
الأوسط (59\189) 5036، من طرقهم عن عطاء، وأمد في مسنده (190\43) 26079، من طريقه عن ابن أبي مليكة، و(43) 279 26220، من طن طريقه أم داود،

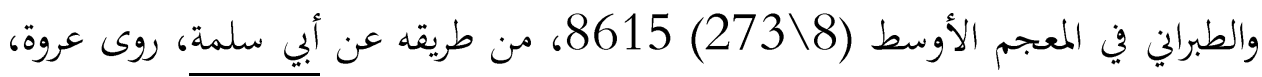

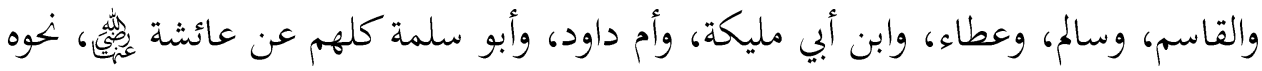

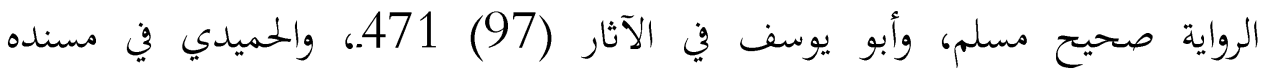
218 264\1) من طريقينهما يُمَّمَ بن المنتشر، عن ابن عمر رضي الله عنهما، سأل ابن المنتشر تطيب الرجل قبل يهرم منعه ثم سأل ابن المنتشر عن عائشة رضي الله عنهما

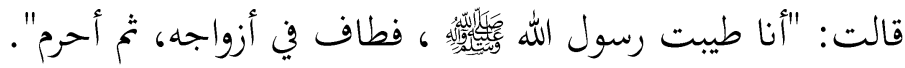
دراسة علة الحديث : رجال الطريق الإما الطبراني: - موسى بن خازم بن سيار 48: ما

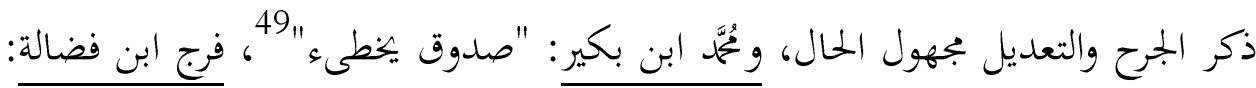

48 - Al-Dhahabi, Shams-ul-Din Abu Abdillah, Tareek Al Islam wa Wafiyat Al Masheer, Al Alaam, V.6, P.1059.

49 - Al-Asqalani, Ibn Hajar, Takreeb Al Tahzeeb, P.470. 
The Scholar Islamic Academic Research Journal

Vol. 6, No. 2 || Janurary-June 2020||P.64-91

https://doi.org/10.29370/siarj/issue11arabic4

"ضعيف"50، وهشام ابن عروة ابن الزبير: "ثقة فقيه"51، وعروة ابن الزبير: "ثقة فقيه"52"،

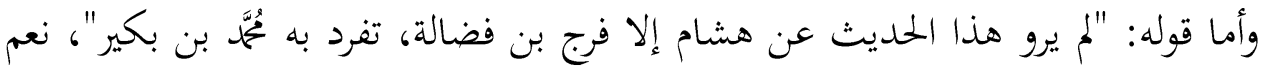

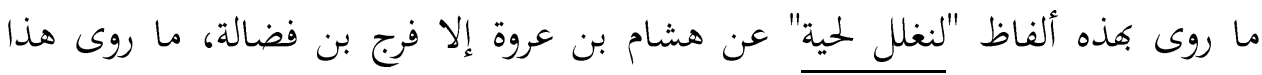

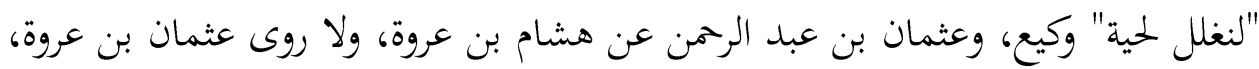

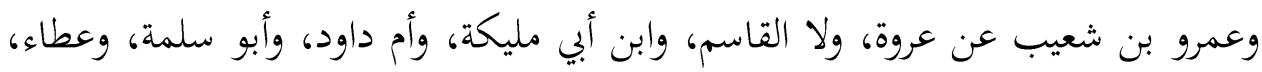
وسالم، وابن عمر رضي الله عنهما عن عائشة رضي الله عنهما، إنما رووا عنها ئهّ: طيبت أم المؤمنين نبي الله إبراز العلة: زيادة في بعض المتن "لنغلل لحية".

رأي الباحث قلت: طريق الإمام الطبراني ضعيف، وبعض متن الرواية غير حفوظ، لعدة أسباب 1- ما روى "نغلل لحية" إلا فرج بن فضالة، هذا زيادة غير مقبولة لأنه ضعيف. 2- خخالفة الثقات: ما ذكر وكيع، وعثمان بن عبد الرممن عن هشام، ولا عثمان بن عروة، وعمرو بن شعيب عن عروة، تطيب (تغلل) لحية إلا فرج بن فضالة. 3- خخالفة الجماعة: ما روى القاسم، وابن أبي مليكة، وأم داود، وأبو سلمة وعطاء، وسالم وابن عمر رضي الله عنهما عن عائشة ئفئ: تغلل لحية.

\footnotetext{
${ }^{50}$ - Al-Asqalani, Ibn Hajar, Takreeb Al Tahzeeb, P.444.

51 - Al-Asqalani, Ibn Hajar, Takreeb Al Tahzeeb, P.573.

52 - Al-Asqalani, Ibn Hajar, Takreeb Al Tahzeeb, P.389.
} 


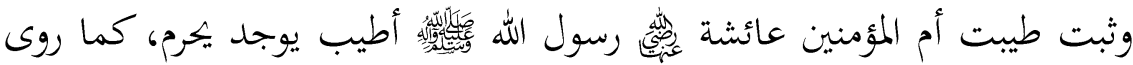

الإمام مسلم في صحيحه عن عائشة ئ山⿶凵، قالت: "كنت أطيب رسول الله صلى الله

عليه وآله وسلم بأطيب ما أقدر عليه قبل أن يُحرم"، قد روى الإمام البخاري، والإمام ابن حبان، في صحيحينهما بألفاظ متقاربة.

\section{مثال الخامس علة مؤثرة من تغير عدد لا يمكن قبول تفاوتما:}

قال الإمام الطبراني رممه الله: حدثنا موسى بن هارون، نا إسحاق بن راهويه،

أنا الفضل بن موسى، عن الحسين بن واقد، عن علباء بن أحمر اليشكري، عن عكرمة،

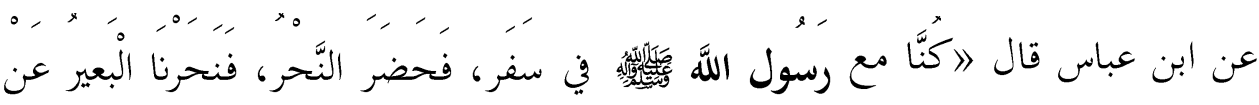

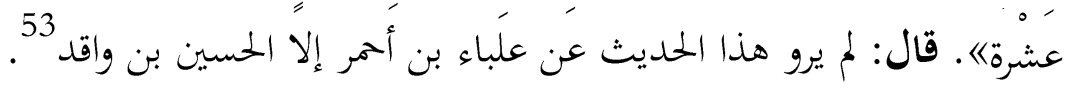

ألفاظ المثكلة: البعير: "ما صلح للركوب والحمل من الإبل وذلك إذا استكمل أربع

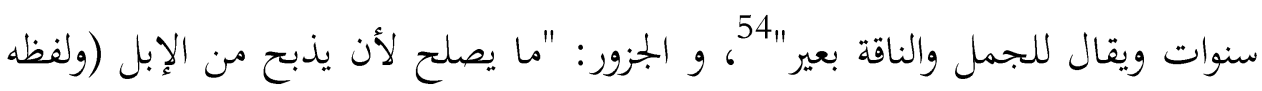

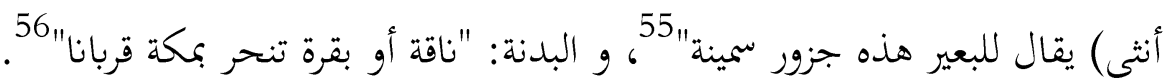

تخريج الحديث: أخرج الأئمة: الترمذي في سنه (494) 1501، وأحمد في مسنده 2484 287\4، والنسائي في سننه (222\7) 4392، وابن ماجه في سننه

\footnotetext{
53 - Al Tabrani Abu Al Qasim Sulemaan bin Ahmed, Al Mujam Al Awast, V.8, P.114, Hadith no: 8132.

${ }^{54}$ - Al Mujam Al Waseet, Majmuh Al Lugat Al Arbiya, V.1, P.63.

55 - Al Mujam Al Waseet, Majmuh Al Lugat Al Arbiya, V.1, P.120.

${ }^{56}$ - Al Mujam Al Waseet, Majmuh Al Lugat Al Arbiya, V.1, P.44.
} 
3131 1047\2) وابن خزيمة في صحيحه (291\4) 2908، من طرقهم عن

الفضل بن موسى عن حسين بن واقد عن علباء بن أحمر عن عكرمة عن ابن عباس رضي

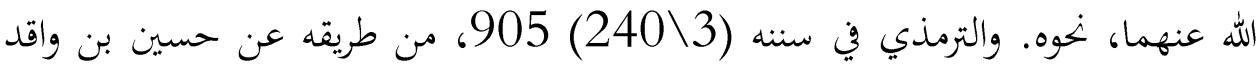

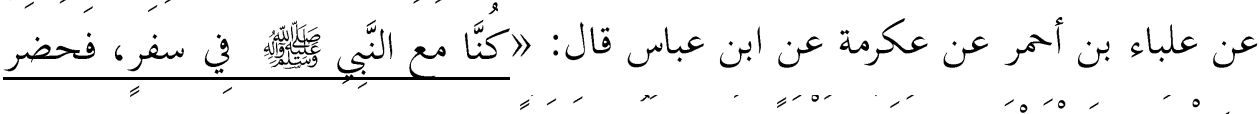

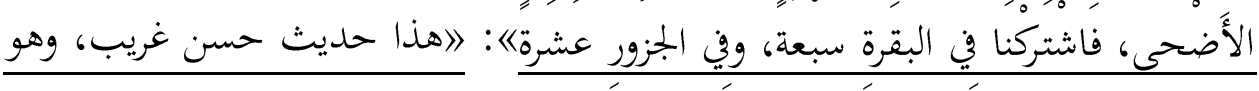
حديث حسين بن واقدها.

دراسة علة الحديث: رجال الطريق الإمام الطبراني: - موسى بن هارون: "ثقة حافظ"57"،

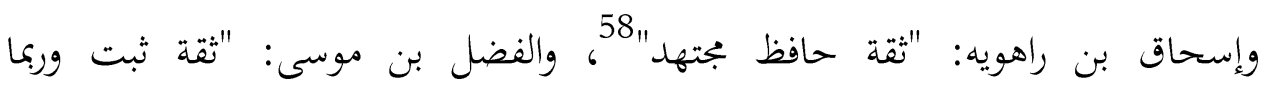

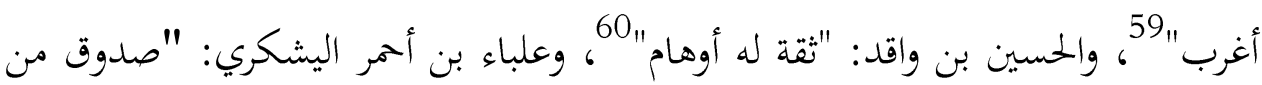

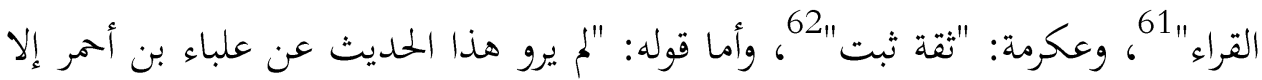

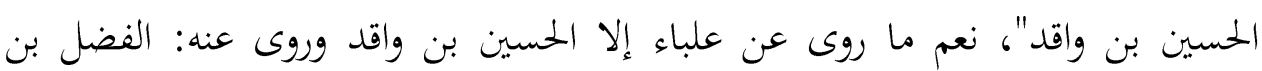
موسى تفرد الحسين بن واقد في المثن "البعير عن عشرة". إبراز العلة: تغير في المتن "البعير عن عشرة".

\footnotetext{
57 - Al-Asqalani, Ibn Hajar, Takreeb Al Tahzeeb, P.554.

58 - Al-Asqalani, Ibn Hajar, Takreeb Al Tahzeeb, P.99.

59 - Al-Asqalani, Ibn Hajar, Takreeb Al Tahzeeb, P. 447.

60 - Al-Asqalani, Ibn Hajar, Takreeb Al Tahzeeb, P.169.

${ }^{61}$ - Al-Asqalani, Ibn Hajar, Takreeb Al Tahzeeb, P.397.

${ }^{62}$ - Al-Asqalani, Ibn Hajar, Takreeb Al Tahzeeb, P.397.
} 
رأي الباحث قلت: طريق الإمام الطبراني لا يبلغ درجة الصحة، تغيير في المتن غير مقبول

1- تفرد : ما روى "البعير عن عشرة"، إلا الحسين بن واقد، وهو ثقة وله أوهام، وتفرده لا يقبل منه.

2- خخالفة أكثر وأصح الطرق منها روى الأئمة: مالك في موطأ (برواية يجيى الليثي)

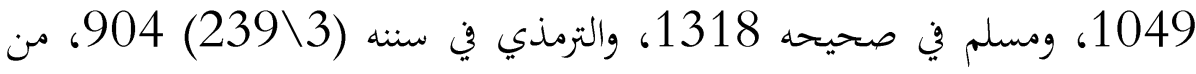

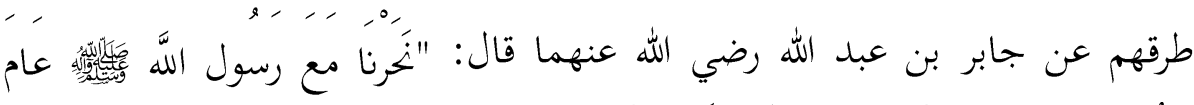

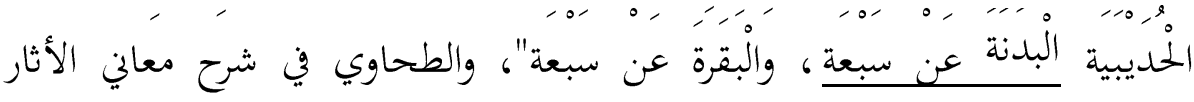

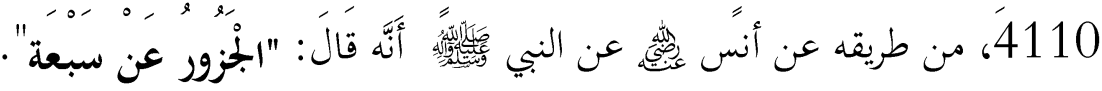

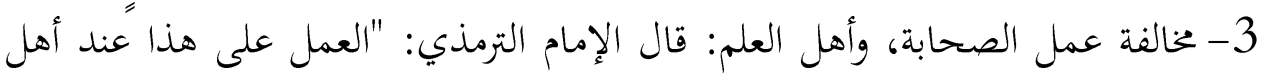
العلم من أصحاب النبي

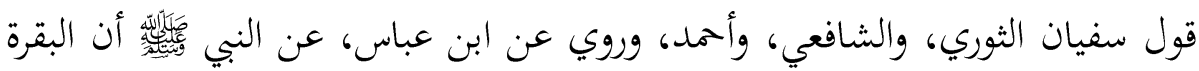
عن سبعة، والجزور عن عشرة، وهو قول إسحاق، واحتج بهذا الحديث، وحديث ابن

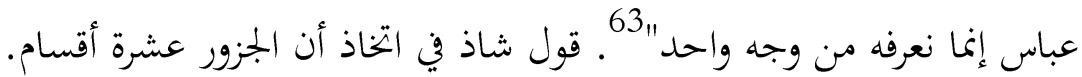
4- ترجيح الأئمة: رجح الثوري، والشافعي، وأحمد، ومسلم، والبيهقي، غيرهم، قال الإمام البيهقي: "ورجح مسلم بن الحجاج روايتهم لما خرجها دون رواية غيرهم.. وحديث

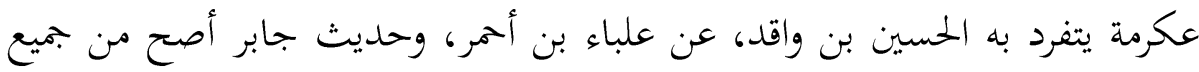
ذلك وأخبر باشتراكهم فيها في الحج والعمرة وبالحديبية بأمر رسول الله صلى الله عليه

${ }^{63}$ - Al Termzi Abu Esa Muhammad Bin Esa, Al Jameh Al Kabeer (Sunnan Al Termzi), Dar Al Garb Al Islami, Beirut, 1998, V.2, P.240, Hadith n.o: 904. 
وسلم فهو أولى بالقبول"64. زيادة عدد في حصة البعير من الحسين بن واقد لا يقبل، فهذا لا ينجبر لأن مخالفة أصح، وأكثر.

\section{مثال السادس علة مؤثرة من تغير ألفاظ التى خالف متنها، وسائر قصتها:}

قال الإمام الطبرالي رحمه الله: حدثنا موسى بن زكريا، ثنا يُمَّهَ بن يهيى القطيعي،

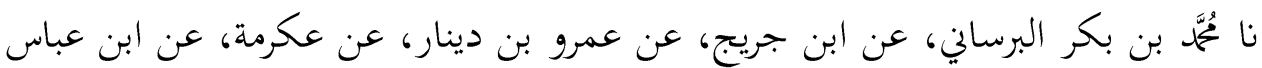

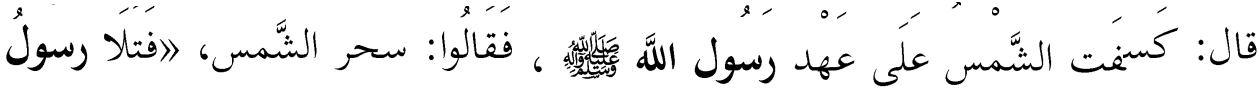
اللَّه

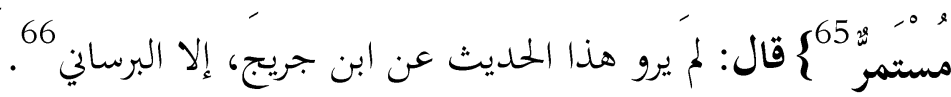

تخريج الحديث: روى الطبراني في المعجم الكبير (250\11) 11643، عن عبدان بن أحمد، ثنا أيوب بن ثُمَّمَ الوزان، ثنا يهيى بن داود، ثنا إبراهيم بن يزيد عن عمرو بن دينار، عن عكرمة، عن ابن عباس، قال: 》انكسفت الشمس على عهد رسول الله

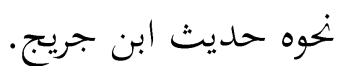
ممن روى كسف أو شق القمر غير كسفت الشمس: روى الإئمة: البخاري في صحيحه 3638، ومسلم في صحيحه (207\4) 2159) 48 - 2803، والطحاوي في

\footnotetext{
${ }^{64}$ - Al Behaqi Abu Bakr Ahmed Bin Al Hussain, Al Sunnan Al Kubra, Dar Al Kutb Al Almiyaht, Beirut, 2003, V.5, P.386.

${ }^{65}$ - Al Quran Al Hakeem, Surah: 54, Ayat: 1-2.

66 - Al Tabrani Abu Al Qasim Sulemaan bin Ahmed, Al Mujam Al Awast, V.8, P.175, Hadith no: 8315.
} 
شرح مشكل الآثار (180\2) 704، من طرقهم عن عبيد الله بن عبد الله بن مسعود

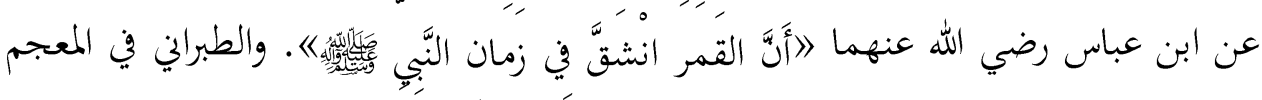

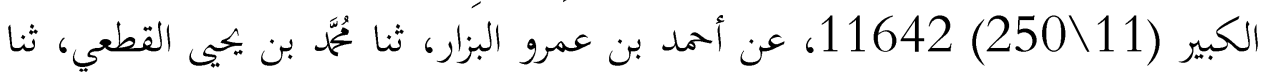
مُعْمَّ بن بكر، ثنا ابن جريج، عن عمرو بن دينار، عن عكرمة، عن ابن عباس، قال: "

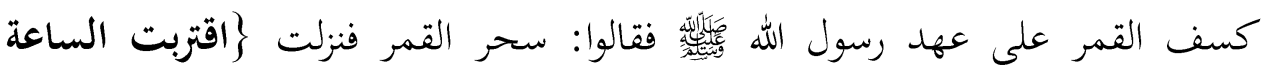
وانشق القمر إلى قوله \}مستمر ك، وأبو نعيم في دلائل النبوة (279) 209، من طريقه عن الضحاك عن ابن عباس رضي الله عنهما، ذكر القصة انشقاق القمر مفسرا .

دراسة علة الحديث: رجال الطريق الإمام الطبراني: - موسى بن زكريا التستري: "ضعيف

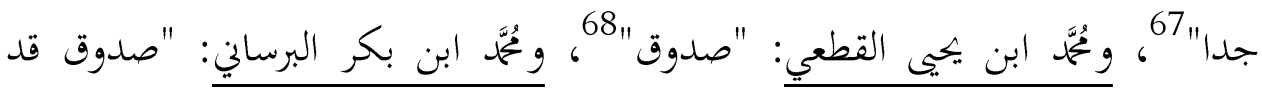

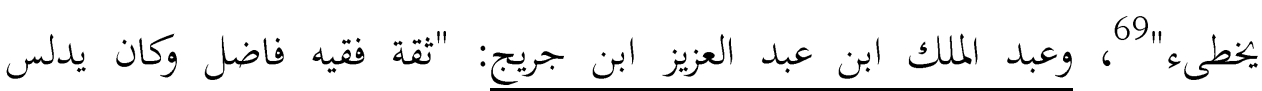

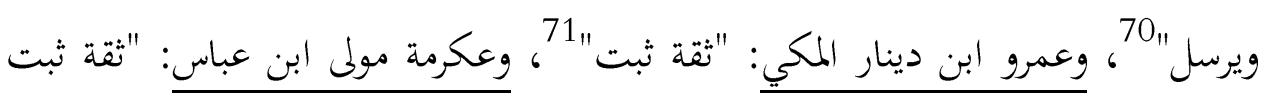

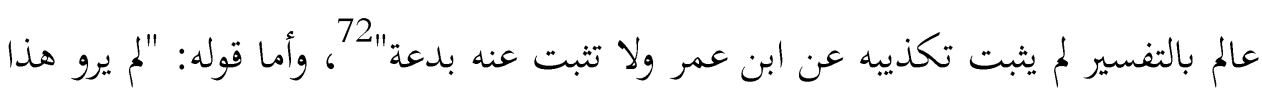

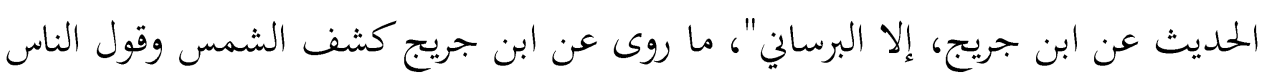

${ }^{67}$ - Al Munsori Abu Al Tiyab Nayaf Bin Salah, Arshad Al Qasi W Dani Ela Tarajm Sheyok Al Tabrani, Dar Al Kiyaan, Al Riyaaz, P.655-656.

68 - Al-Asqalani, Ibn Hajar, Takreeb Al Tahzeeb, P.512.

69 - Al-Asqalani, Ibn Hajar, Takreeb Al Tahzeeb, P.470.

70 - Al-Asqalani, Ibn Hajar, Takreeb Al Tahzeeb, P.363.

71 - Al-Asqalani, Ibn Hajar, Takreeb Al Tahzeeb, P.421.

72 - Al-Asqalani, Ibn Hajar, Takreeb Al Tahzeeb, P.397. 


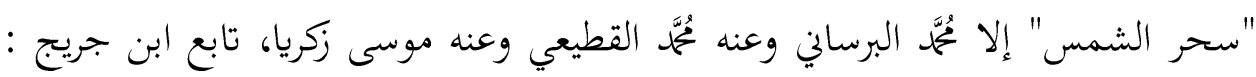
إبراهيم بن يزيد ولكن متروك الحديث 73.

إبراز العلة: تغيير في المتن "كسفت الشمس".

رأي الباحث قلت: طريق الإمام الطبراني ضعيف، ومتنها غير محفوظ لعدة أسباب 1- طريق الإمام الطبراني ضيعف فيها موسى بن زكريا ضعيف جدا.

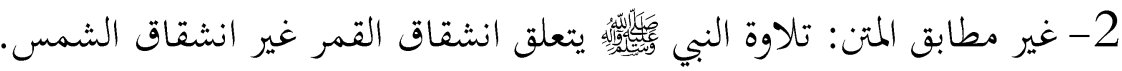

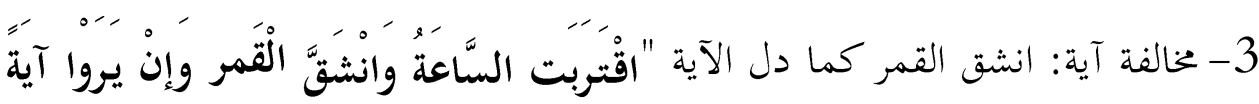

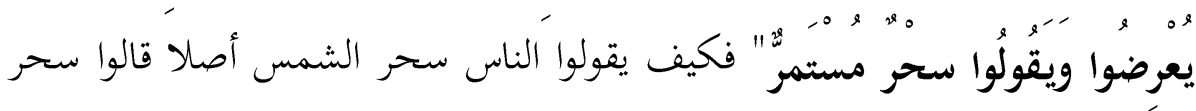

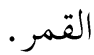

4- خخالفة الطرق الصحيحة: روى الإمام البخاري، والإمام مسلم في صحيحينهما عن ابن عباس رضي الله عنهما، ذكرا انشق القمر. 5- اختلف الراويان في شيخهما في روايته: روى موسى بن زكريا، عن تُمَّمَ بن يهيى القطيعي، عن يُمَّمَ بن بكر البرساني ذكر كسفت الشمس، وروى عن أحمد بن عمرو

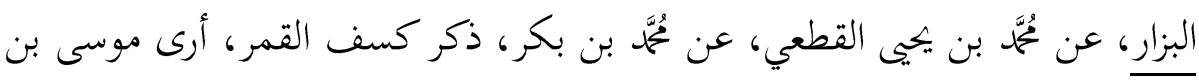
زكريا أخطأ وهو ضعيف جدا، والرواية أحمد البزار صحيح لمتابعات. 6- خخالفة الرواة: روى عبيد الله بن عبد الله بن مسعود، والضحاك، وعكرمة (من طريق أحمد البزار) عن ابن عباس رضي الله عنهما، ذكروا انشقاق القمر دون ذكر الشمس.

\footnotetext{
73 - Al-Asqalani, Ibn Hajar, Takreeb Al Tahzeeb, P.95.
} 
نتائج البحث: من خلال هذا البحث يظهر لي أن تغير ألفاظ المتون لها عدة أقسام. 1- تغيير قد تكون أختلاف ألفاظ، واتحاد معنى كما بينت في مثال الأول ممكن جمع بين

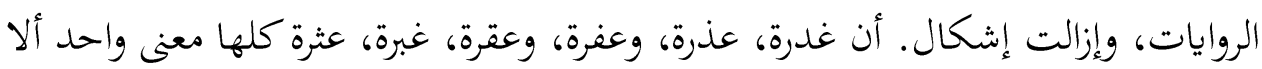
هي لا تنبت وتحمل ولا تعمر.

2- تغيير قد تكون تبديل وتنقيص بعض ألفاظ ببعض كما بينت في مثال الثاني لا يمكن اتحاد ألفاظ ولا معاني لأن استعار وضمن مختلف تماما القصة الصحيحة أصل هو اهدت

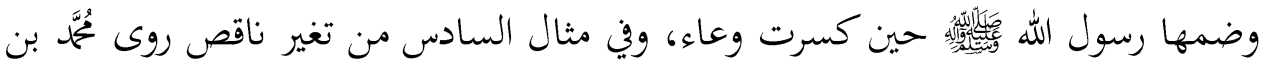
بكر أن كسفت الشمس خالفه أكثر وأصح الطرق أن انشق القمر ليس كسفت الشمس، والآية نزلت في شأن انشاق القمر وهذا واضح بالآية الكريمة.

3- تغيير قد تكون زيادة لفظا غير مقبولا، وبقي ألفاظ صحيح بمتابعات وبشواهد، كما

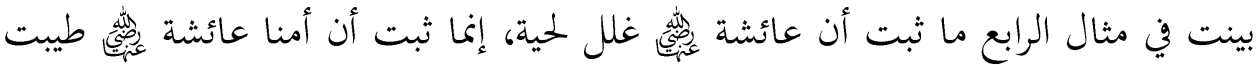

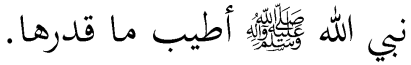
4- تغيير قد تكون غير مقبول لفظا ومقبول معنا كما بينت في مثال الثالث "صوموا تصحوا" ما تصح سندا، ولكن ثبت معنا من حديث من لم يستطيع زواج أوصى رسول الله

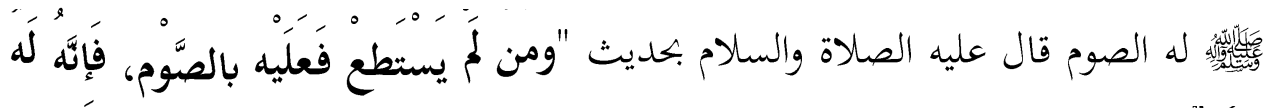
وجَاء" "14، الصوم وجاء من شهوات.

74_ Al Bukari Muhammad Bin Ismael, Al Jamih Al Musnad Al Shahi AlMuktsir Min Umoor Rasool Allah Sal Allah Alih Wa Aalhi Waslam Wa Sunnanhe Wa Ayaamhe (Sahi Bukari), Dar Toq Al Najat, 1422 A.H, V.3, P26, Hadith no: 1905. 
5- تغيير قد تكون تقديما وتأخيرا كما بينت الرواية زهير عن سهيل بن أبي صالح عن أبيه

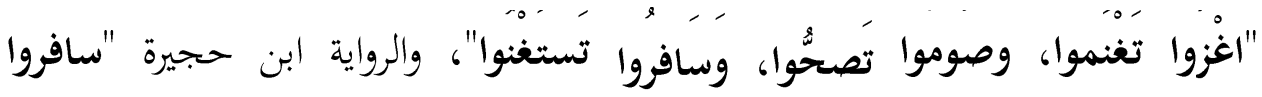
تصحوا، واغزوا تستغنوا"، قدم زهير سفر وَأخر غزو.

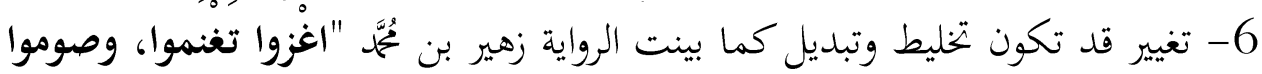

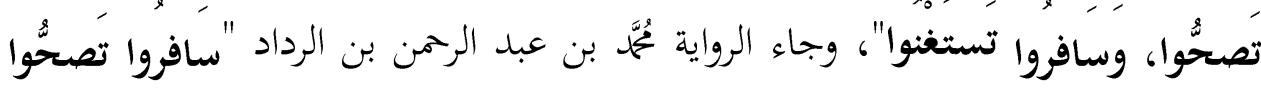

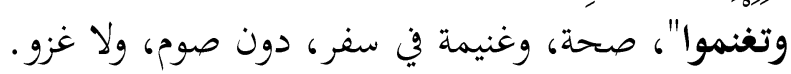
7- تغيير قد تكون زيادة عدد كما بينت في مثال الخامس رواية الحسين بن واقد تدل أن حصة البعير بعد نخرها عند قربان عشرة، وأصح وأكثر الطرق تدل خلاف ذلك أن حصتها سبعة ليس عشرة. 8- تفرد الراوي الثقة أغلب مقبول منه كما بينت في مثال الأول تفرد عبدة بن سليمان حين يروي عذرة، وهذا مقبول حينما جمعت طرق الحديث بين لي أن تفرده غير مؤثر، لأن إختلاف ألفاظ الحديث دون إختلاف معناها. 9- قد تكون تفرد الراوي الثقة وله أوهام لا يقبل تغير في روايته كما بينت في مثال الخامس روى الحسين بن واقد البعير عن عشرة وهذا غير مقبول عندما نظرنا جميع طرق الحديث، إنما روى أكثر وأصح هو الجزور أو البعير أو البدنة عن سبعة. 10- قد تكون تفرد الراوي صدوق قد يخطئ لا يقبل تغير في روايته كما بينت مثال

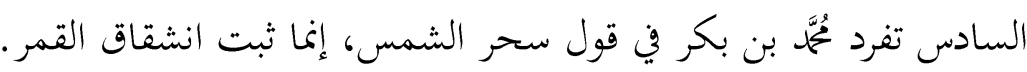
11- أن أغلب الرواة الضعفاء في تغير رواياقم غير مقبولة، كتفرد سويد بن عبد العزيز، وفرج بن فضالة، وموسى بن زكريا ما تبع ولا قبل تفرداتمه. 


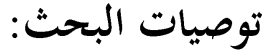

أن تغير ألفاظ المتن لا يقبل مطلقا ولا يرد مطلقا إنما ينظر جميع طرقها، وينظر أحوال راوتا، وصحتها، ويتألف متوها، وينظر معاني ألفاظ مختلفة بما يتفتها ويختلفها، وقد تكون تغيير زيادة لفظها دون معناها، وقد تكون نقص في معناها، وقد تكون تشريح معنى الحديث، وقد تكون روى الراوي أو المصنف الحديث مختصرا وغيره مطولا، فينظر أقوال المحدثين والفقهاء حتى يتبين ما هو الصواب.

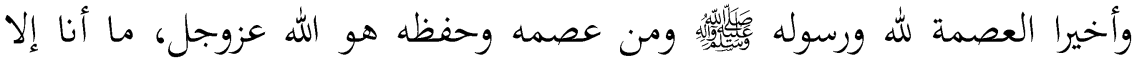
بشر أصيب وأخطئ إن أصبت فمن الله تعالى، وإن أخطأت فمن نفسي، اللهم صل وسلم وبارك على رسولك الذي قلت في شأنه "وما أرسلناك إلا رحمة للعالمين"، وآله، وأصحابه، وأتباعه، وجعلني منهم، وأمي، وأبي، وزوجتي، وأخوتي، وأخواني، وأساتذتي، وأقربائي، وأصدقائي، وجميع المؤمنين والمؤمنات، والمسلمين، والمسلمات، آمين.

\section{(c) $(1)(9(9)$}

This work is licensed under a Creative Commons Attribution-NonCommercial-ShareAlike 4.0 International (CC BY-NC-SA 4.0) 